\title{
Single-center In-hospital Cardiac Arrest Outcomes
}

\author{
Leonard E Riley ${ }^{1}$, Hiren J Mehta ${ }^{2}$, Jorge Lascano ${ }^{3}$
}

\begin{abstract}
Background: This study was designed to evaluate the patient characteristics and outcomes of in-hospital cardiac arrest (IHCA).

Materials and methods: We carried out a single-center, 5-year, retrospective chart review and analysis of resuscitation data for age, gender, body mass index (BMI), length of stay (LOS) until cardiac arrest, survival of initial IHCA, survival to hospital discharge, primary medical service, and determination of the etiology of cardiac arrest.

Results: A total of 500 cases occurred with a mean LOS of 8.5 days until the initial IHCA. Overall, $79.5 \%$ survived the initial IHCA and $32.4 \%$ survived to discharge. As LOS increased, there was an increase in the proportion of pulmonary and metabolic etiologies. Logistic regression analysis adjusting for BMI, gender, age, LOS, and primary medical service were on a surgical service significant for survival to discharge $(p=$ $0.0007)$ and LOS $<9$ days significant for survival of IHCA $(p=0.018)$.

Conclusion: There are a number of causes of IHCA, and the incidence of death and respiratory related IHCA etiologies increase with LOS. Length of stay carries the highest weight when predicting survival of IHCA. Also, there is a higher rate of survival to discharge when on a primary surgical service.

Keywords: Advanced life support, Cardiac arrest, Cardiopulmonary resuscitation, Causes of cardiac arrest, In-hospital cardiac arrest. Indian Journal of Critical Care Medicine (2020): 10.5005/jp-journals-10071-23327
\end{abstract}

\section{INTRODUCTION}

Sudden cardiac arrest is defined by the American College of Cardiology and American Heart Association (AHA) as, "sudden cessation of cardiac activity so that the victim becomes unresponsive, with no normal breathing and no signs of circulation." ${ }^{1,2}$ It is estimated that approximately 292,000 adult IHCAs are treated annually in the United States. ${ }^{3}$ The AHA identifies hypovolemia, hypoxia, hydrogen ion (acidosis), hypokalemia, hyperkalemia, hypothermia, tension pneumothorax, cardiac tamponade, toxins, pulmonary thrombosis, and coronary thrombosis as reversible etiologies of cardiac arrest to include, which are colloquially known as the H's and T's. ${ }^{4}$ Studies have described the etiology prevalence of in-hospital cardia arrest (IHCA) in the United States; however, there are limited data describing the patient characteristics and patterns in survivability with relation to length of stay (LOS), etiology, and primary service. ${ }^{5-10}$ We aimed to describe the patient characteristics, survivability of IHCA as well as survival to discharge, and the effect different parameters have on predicting survival.

\section{Materials and Methods}

This study was approved by the Institutional Review Board (201702489) for the University of Florida Health (Gainesville, Florida, USA), which is a tertiary care center with over 950 beds. We carried out a single-center retrospective chart review of patients admitted from January 1, 2012, to December 31, 2017 who had the principal diagnosis of cardiac arrest after presentation to the hospital. Our institutional review board waived the need for written informed consent. The inclusion criteria were both males and females who were between 18 years and 90 years of age who had a cardiac arrest after presentation to the hospital and received full resuscitative measures according to the AHA's advanced cardiac life support (ACLS). ${ }^{4}$ The exclusion criteria were patients undergoing cardiopulmonary resuscitation at the time of arrival
${ }^{1-3}$ Department of Medicine, Division of Pulmonary, Critical Care and Sleep Medicine, University of Florida, Gainesville, Florida, USA

Corresponding Author: Leonard E Riley, Department of Medicine, Division of Pulmonary, Critical Care and Sleep Medicine, University of Florida, Gainesville, Florida, USA, Phone: +1-352-273-8734, e-mail: Elmer.Riley@medicine.ufl.edu

How to cite this article: Riley LE, Mehta HJ, Lascano J. Singlecenter In-hospital Cardiac Arrest Outcomes. Indian J Crit Care Med 2020;24(1):44-48.

Source of support: The Research reported in this publication was supported by the National Center for Advancing Translational Sciences of the National Institutes of Health under University of Florida Clinical and Translational Science Awards UL1 TR000064 and UL1TR001427

Conflict of interest: None

or before arrival to the hospital or did not receive full resuscitative measures according to ACLS. ${ }^{4}$ In cases where a patient experienced more than one IHCA during a hospitalization, only the initial IHCA event was evaluated.

All clinical data were extracted from the patient's records, including age, gender, body mass index (BMI), primary admitting service, admission etiology, IHCA etiology, and LOS until IHCA, survival of IHCA, and survival to hospital discharge. In-hospital cardiac arrest etiology was categorized into eight groups, such as pulmonary, cardiac, exsanguination, aortic injury, metabolic, cerebral, adverse drug reaction, or unknown ${ }^{11}$ (Table 1). Patients were designated to one of these groups by identifying documentation of the etiology by the primary healthcare team or upon autopsy. If an autopsy and the primary healthcare team did not identify an etiology, then the IHCA etiology was assigned as unknown. No autopsies or tests were performed for the sole purpose of this study.

(0) The Author(s). 2020 Open Access This article is distributed under the terms of the Creative Commons Attribution 4.0 International License (https://creativecommons. org/licenses/by-nc/4.0/), which permits unrestricted use, distribution, and non-commercial reproduction in any medium, provided you give appropriate credit to the original author(s) and the source, provide a link to the Creative Commons license, and indicate if changes were made. The Creative Commons Public Domain Dedication waiver (http://creativecommons.org/publicdomain/zero/1.0/) applies to the data made available in this article, unless otherwise stated. 
Table 1: Patient demographics

\begin{tabular}{lll}
\hline Demographic & $n$ & $\%$ \\
\hline Female & 190 & 38 \\
Male & 310 & 62 \\
Age mean \pm SD (years) & $60.9 \pm 16.0$ & \\
BMI mean \pm SD $\left(\mathrm{kg} / \mathrm{m}^{2}\right)$ & $28.6 \pm 8.5$ & \\
Length mean \pm SD (days) & $8.5 \pm 19.5$ & \\
Survived IHCA (yes) & 398 & 79.6 \\
Survived IHCA (no) & 102 & 20.4 \\
Survived to discharge (yes) & 162 & 32.4 \\
Survived to discharge (no) & 338 & 67.6 \\
Unknown etiology & 249 & 49.8 \\
Pulmonary etiology & 119 & 23.8 \\
Cardiovascular etiology & 68 & 13.6 \\
Exsanguination etiology & 22 & 4.4 \\
Aortic injury etiology & 15 & 3.0 \\
Metabolic etiology & 14 & 2.8 \\
Cerebral etiology & 6 & 1.2 \\
Adverse drug reaction etiology & 6 & 1.2 \\
\hline
\end{tabular}

\section{Statistical Analysis}

Demographic and clinical characteristics of patients were evaluated with between-group differences. We used paired $t$ test to analyze the effects of sex, age, BMI, LOS, and admitting service over survival of IHCA and survival to discharge. To examine the association between survival of the arrest and survival to discharge and known cofounders, multivariable logistic regression analysis was used with survival as the exposure variable. The model included important cofounders, including age, sex, BMI, hospital service, and days of hospitalization before the arrest. All $p$ values represent 2-sided hypothesis test. The significance level for all test was alpha $<0.05$. Analysis were performed with GraphPad Prism, version 7.0 (GraphPad Software Inc., La Jolla, California).

\section{Results}

\section{Patients}

In total, 500 IHCA events were identified and all 500 patients' charts were reviewed. Patient characteristics are shown in Table 1. The study included 310 men (62\%) and 190 women (38\%) with a mean age of $60.9 \pm 16.0$ years. The mean BMI was $28.6 \pm 8.5 \mathrm{~kg} / \mathrm{m}^{2}$. The mean LOS until the initial IHCA was $8.5 \pm 19.5$ days. Of the 500 patients, 398 (79.6\%) survived the initial IHCA and 162 (32.4\%) survived to hospital discharge (Table 1). A logistic plot model demonstrates the probability.

There were 25 different services listed as primary providers for these patients (Table 2). The three services with the most IHCA were the medical intensive care unit (MICU) with 109 cases (21.8\%), thoracic/cardiovascular surgery with 70 cases (14.0\%), and internal medicine with 67 cases (13.4\%) (Table 2).

\section{Etiologies and Causes}

The etiology and examples of the IHCA were categorized as pulmonary (119 cases), cardiovascular (68 cases), exsanguination (22 cases), aortic injury (15 cases), metabolic (14 cases), cerebral (6 cases), adverse drug reaction (6 cases), or unknown (249 cases) ${ }^{11}$ (Table 1). Hypoxia was identified to be the most common cause with 102 cases (20.4\%) followed by arrhythmia in 31 cases (6.2\%),
Table 2:Ten primary medical services with the most in-hospital cardiac arrest (IHCA)

\begin{tabular}{llll}
\hline Services & & $\begin{array}{l}\text { Average LOS } \\
\text { until IHCA (days) }\end{array}$ & $\begin{array}{l}\text { Survived to } \\
\text { discharge n (\%) }\end{array}$ \\
\hline $\begin{array}{l}\text { Medical intensive } \\
\text { care unit }\end{array}$ & $109(21.8)$ & 8.0 & $22(20.2)$ \\
$\begin{array}{l}\text { Thoracic/ } \\
\text { cardiovascular }\end{array}$ & $70(14.0)$ & 5.5 & $33(47.1)$ \\
$\begin{array}{l}\text { surgery } \\
\text { Internal medicine }\end{array}$ & $67(13.4)$ & 12.8 & \\
$\begin{array}{l}\text { Vascular } \\
\text { Cardiology }\end{array}$ & $63(12.6)$ & 8.4 & $17(25.4)$ \\
$\begin{array}{l}\text { Trauma } \\
\text { Neurosurgery }\end{array}$ & $33(10.2)$ & 5.9 & $16(25.4)$ \\
Neurology & $22(4.4)$ & 15.0 & $18(35.3)$ \\
$\begin{array}{l}\text { Pancreaticobiliary } \\
\text { surgery }\end{array}$ & $17(3.4)$ & 7.0 & $9(48.5)$ \\
$\begin{array}{l}\text { Kidney, liver, } \\
\text { pancreas transplant }\end{array}$ & $10(2.0)$ & 24.1 & $8(47.1)$ \\
\hline
\end{tabular}

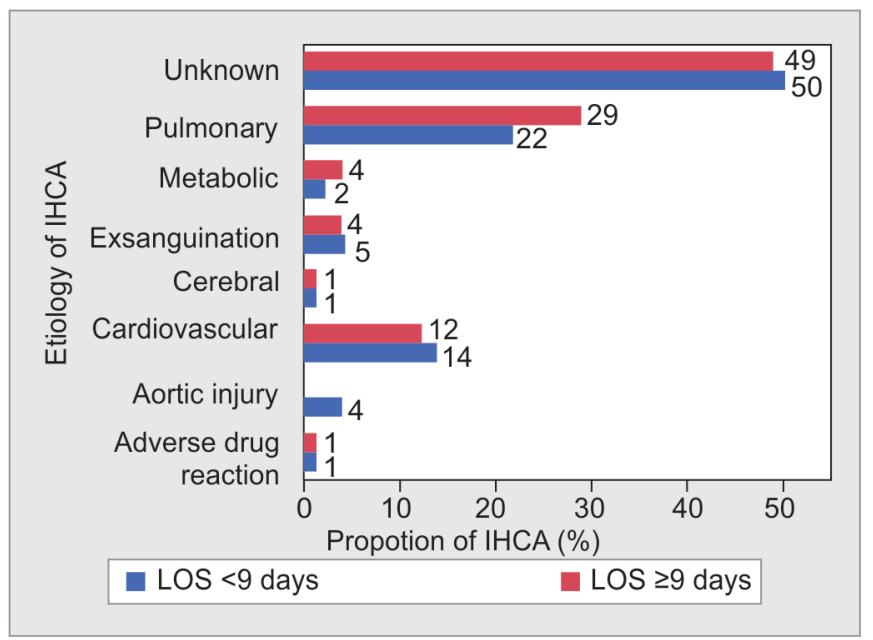

Fig. 1: Proportion of etiology of in-hospital cardiac arrest grouped by length of stay $<9$ days or $\geq 9$ days

myocardial infarction in 20 cases (4\%), hypovolemia in 20 cases (4\%), and pulmonary embolism in 13 cases (2.6\%).

When the etiology of IHCA are grouped by LOS $<9$ days or $\geq 9$ days, there is an upward trend in the proportion of IHCA due to pulmonary ( $21.8 \%$ vs $29.0 \%$ ) and metabolic ( $2.3 \%$ vs $4.1 \%)$, whereas all other etiologies decreased in proportion (Fig. 1).

\section{Subgroup Analysis}

Age

Age was divided into two groups, $\leq 60$ or $>60$ years. Of the patients $\leq 60$ years old, 183 survived and 41 died following the initial IHCA, whereas 215 survived and 61 died among patients $>60$ years old ( $p=0.026$ ) (Table 3). When evaluated for survival to discharge, 77 survived and 147 died among patients $\leq 60$ years old and 85 survived and 191 died among patients $>60$ years old $(p=0.128)$ (Table 3 ).

\section{Surgical or Nonsurgical Service}

Patients were also divided by primary service as surgical or nonsurgical. The mean LOS for IHCA on the surgical service was $8.3 \pm 15.0$ days, and the mean LOS on the medical service until 
Single-center In-hospital Cardiac Arrest Outcomes

\begin{tabular}{|c|c|c|c|c|}
\hline & Survived (\%) & Died (\%) & Total & $p$ value \\
\hline \multicolumn{5}{|l|}{ Survival of initial IHCA } \\
\hline Age $\leq 60$ years & $183(81.7)$ & $41(18.3)$ & 224 & 0.026 \\
\hline Age $>60$ years & 215 (77.9) & $61(22.1)$ & 276 & \\
\hline Male & $252(81.3)$ & $58(18.7)$ & 310 & 0.192 \\
\hline Female & $146(76.8)$ & $44(23.2)$ & 190 & \\
\hline Surgical & $190(82.6)$ & $38(16.5)$ & 230 & 0.022 \\
\hline Nonsurgical & $206(76.3)$ & $64(23.7)$ & 270 & \\
\hline $\mathrm{BMI}<30$ & $254(79.6)$ & $65(20.4)$ & 319 & 0.172 \\
\hline $\mathrm{BMI} \geq 30$ & $139(81.3)$ & $32(18.7)$ & 171 & \\
\hline Length of stay $<9$ days & $272(76.6)$ & $83(23.4)$ & 355 & 0.172 \\
\hline Length of stay $\geq 9$ days & $126(86.9)$ & $19(13.1)$ & 145 & \\
\hline \multicolumn{5}{|c|}{ Survival to discharge after IHCA } \\
\hline Age $\leq 60$ years & $77(34.4)$ & $147(65.6)$ & 224 & 0.128 \\
\hline Age $>60$ years & $85(30.8)$ & $191(69.2)$ & 276 & \\
\hline Male & $106(34.2)$ & $204(65.8)$ & 310 & 0.072 \\
\hline Female & $26(29.5)$ & $134(70.5)$ & 190 & \\
\hline Surgical & $69(30.0)$ & $161(70.0)$ & 230 & 0.029 \\
\hline Nonsurgical & $93(34.4)$ & $177(65.6)$ & 270 & \\
\hline $\mathrm{BMI}<30$ & $102(32.0)$ & $217(68.0)$ & 319 & 0.234 \\
\hline $\mathrm{BMI} \geq 30$ & $60(35.1)$ & $111(64.9)$ & 171 & \\
\hline Length of stay $<9$ days & $117(33.0)$ & $238(67.0)$ & 355 & 0.228 \\
\hline Length of stay $\geq 9$ days & $45(31.0)$ & $100(69.0)$ & 145 & \\
\hline
\end{tabular}

IHCA was $8.9 \pm 22.6$ days. Of the patients on a surgical service, 192 survived and 38 died following the initial IHCA; 206 survived and 64 died on nonsurgical services ( $p=0.022$ ) (Table 3 ). When evaluated for survival to discharge, 69 survived and 161 died on surgical services and 93 survived and 177 died on nonsurgical services ( $p=0.029$ ) (Table 3). The three most frequent etiologies of IHCA for patients on a surgical service was unknown (43.9\%), pulmonary (25.7\%), and cardiovascular (12.2\%). Nonsurgical services had the same three most common IHCA etiology; however, the frequency was different, with unknown (54.6\%), pulmonary $(22.1 \%)$, and cardiovascular (14.8\%).

\section{Gender}

The patients were comprised of 310 males (62\%) and 190 females (38\%). Two-hundred and fifty-two (81.3\%) male patients survived, and 58 (18.7\%) died following the initial IHCA, while $146(76.8 \%)$ female patients survived and $44(23.2 \%)$ died $(p=0.192)$ (Table 3 ). When evaluated for survival to discharge, 106 (34.2\%) survived and 204 (65.8\%) died among males and 56 (29.5\%) survived and 134 (70.5\%) died among females ( $p=0.072$ ) (Table 3).

\section{Length of Stay}

Length of stay groups were defined as $<9$ days (355 patients) or $\geq 9$ days (145 patients) prior to the IHCA. Of the patients with LOS $<9$ days, $272(76.6 \%)$ survived and 83 (23.4\%) died following the initial IHCA, whereas 126 (86.9\%) survived and 19 (13.1\%) died with a LOS of $\geq 9$ days ( $p=0.172$ ) (Table 3 ). When evaluated for survival to discharge, $117(33.0 \%)$ survived and $238(67.0 \%)$ died with a LOS of $<9$ days and 45 (31.0\%) survived and 100 (69.0\%) died with a LOS of $\geq 9$ days $(p=0.228$ ) (Table 3 ).

\section{Body Mass Index}

Body mass index groups were defined as those with either $<30 \mathrm{~kg} / \mathrm{m}^{2}$ (319 patients) or $\geq 30 \mathrm{~kg} / \mathrm{m}^{2}$ (171 patients) prior to the IHCA.
Of the patients with $\mathrm{BMI}<30 \mathrm{~kg} / \mathrm{m}^{2}, 254$ (79.6\%) survived and 65 (20.4\%) died following the initial IHCA, whereas 139 (81.3\%) survived and $32(18.7 \%)$ died with a BMI $\geq 30 \mathrm{~kg} / \mathrm{m}^{2}(p=0.17)$ (Table 3 ). When evaluated for survival to discharge, 102 (32.0\%) survived and 217 $(68.0 \%)$ died with a $\mathrm{BMI}<30 \mathrm{~kg} / \mathrm{m}^{2}$ and 60 (35.1\%) survived and 111 (64.9\%) died with a BMI $\geq 30 \mathrm{~kg} / \mathrm{m}^{2}(p=0.23)$ (Table 3$)$.

\section{Logistic Regression Model}

A logistic regression was performed to evaluate the effect of hospital service, age, sex, BMI, and LOS before the arrest over survival of the arrest and survival to discharge. When we examined the survival to discharge, the model was able to predict a better survival in patients on surgical service even after adjusted by age, sex, BMI, and days in the hospital before the arrest, $p=0.009$ (Fig. 2).

When we examine the survival of the cardiac arrest, the model was able to predict survival of the cardiac arrest with a $p$ value of 0.04 . The model explains $15 \%$ of the variance in survival and correctly classified $80 \%$ of the cases with a sensitivity $80 \%$. The interesting finding is that most of the weight was determine by the LOS before the arrest $(p=0.01)$ and not the service where the patient was admitted (Fig. 2). A logistic probability plot model depicts the probability of surviving to discharge by LOS (Fig. 3).

\section{Discussion}

This study demonstrated the frequency and outcomes of IHCA analyzed by BMI, age, LOS, gender, etiology of IHCA, and whether patients were admitted to a surgical or nonsurgical service. As described in previous studies, the occurrence of an IHCA portends a poor prognosis with $79.5 \%$ of patients surviving the initial IHCA and ultimately only $32.4 \%$ of all patients surviving to discharge in our study. ${ }^{5,6,11-13}$ When our population was evaluated by gender, BMI ( $<30 \mathrm{~kg} / \mathrm{m}^{2}$ or $\geq 30 \mathrm{~kg} / \mathrm{m}^{2}$ ), age ( $\leq 60$ or $>60$ years), and LOS until IHCA ( $<9$ days or $\geq 9$ days), there was no difference in outcomes at discharge. Persons aged $\leq 60$ years were more likely to survive the initial IHCA; however, there was only a trend for improved survival to discharge.

Individuals with the initial IHCA occurring in the MICU had the poorest outcomes compared with all other groups with only $20.2 \%$ surviving to discharge, which is similar to the rates published previously. ${ }^{9}$ Expectedly, patients admitted to the MICU have more comorbidities, acute organ failure, history of cancer, presence of mechanical ventilation, and/or use of vasoactive medications, which are established associations with not surviving to discharge after IHCA. ${ }^{9}$

There was an improved outcome for survival to discharge for patients admitted to surgical compared with medical services. We postulate the etiology of IHCA, average LOS, and level of acuity may contribute to this. Our model was able to confirm that shorter LOS has the highest weight predicting who will survive the arrest regardless of any other variable. Unknown causes of IHCA led to 148 cases $(54.6 \%)$ on nonsurgical services compared with 101 cases $(43.9 \%)$ on surgical services, with a between-group percent difference of $10.7 \%$. This discrepancy is a direct reflection of the lack of identifying a cause and possibly a lack of identifiable treatment. We also suspect that there may have been a difference in the level of acuity, complexity of comorbidity, and mortality risk for surgical vs nonsurgical patients. If the data was available to evaluate each patient for Acute Physiology and Chronic Health Evaluation II or Sequential Organ Failure Assessment score, we may have been able to investigate this further. 

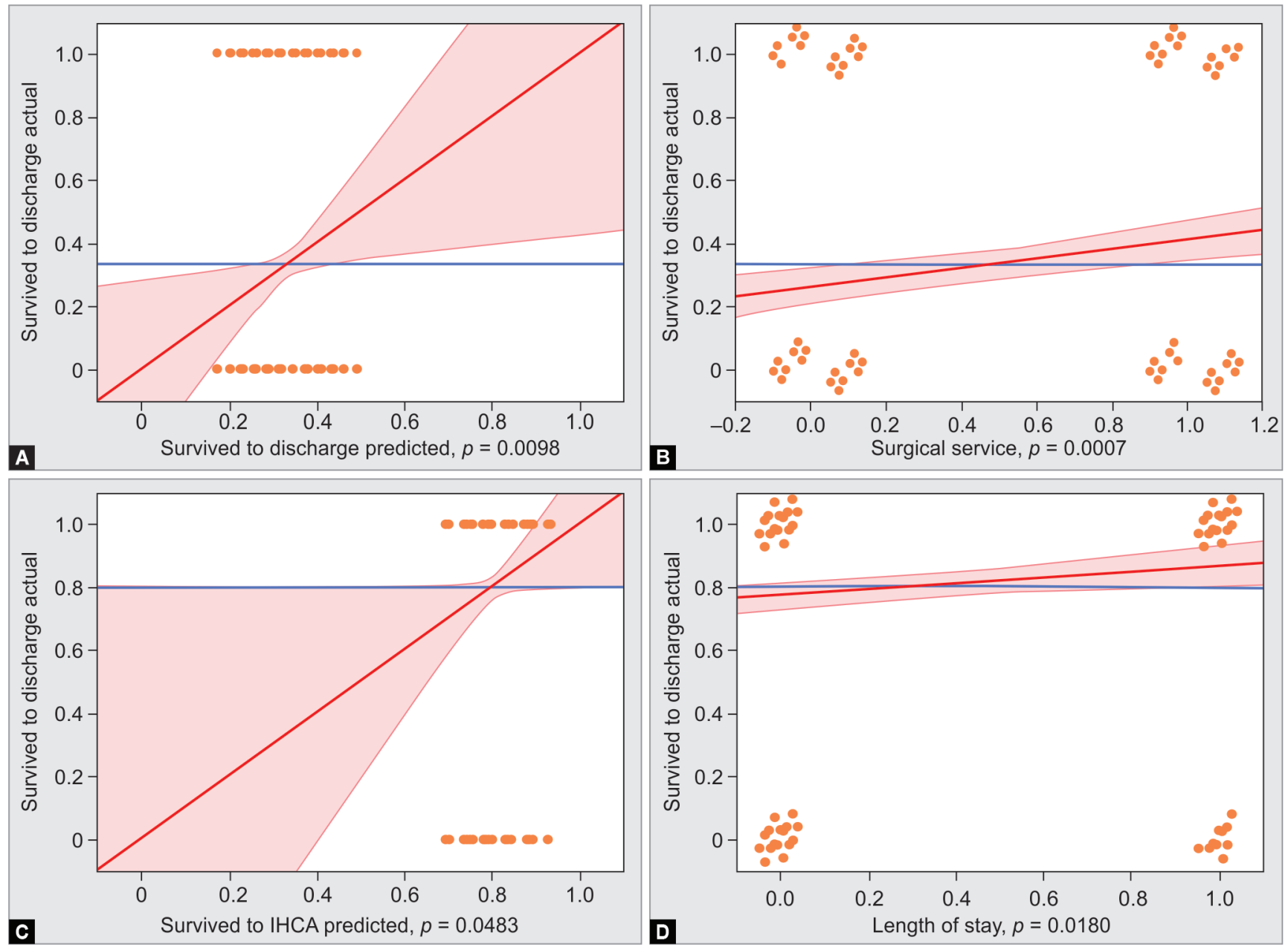

Figs $2 A$ to D: Logistic regression analysis adjusted for gender, age, body mass index, surgical service, and length of stay; (A) Actual and predicted survival to discharge; (B) Survival to discharge on surgical service; (C) Actual and predicted survival of in-hospital cardiac arrest; (D) Survival of in-hospital cardiac arrest by length of stay

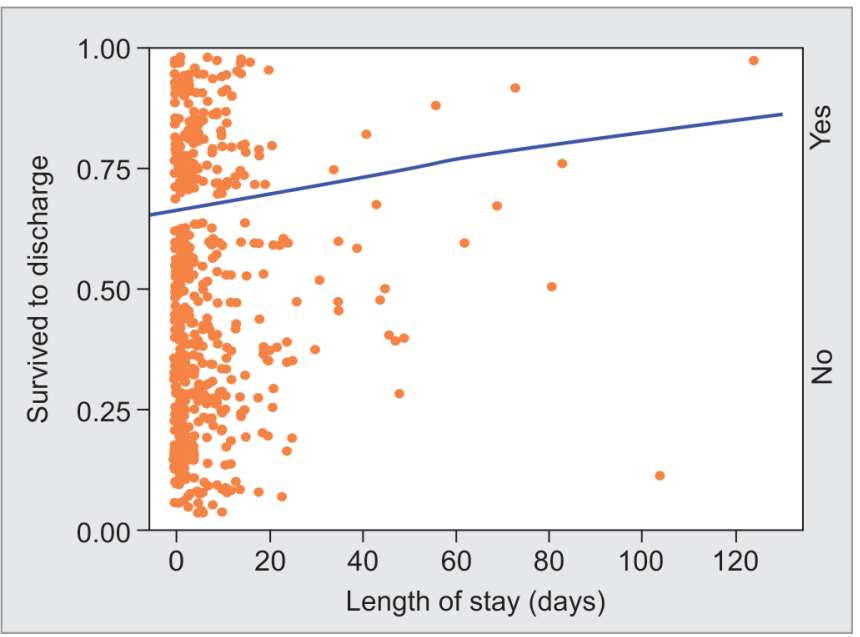

Fig. 3: Logistic probability plot of survival to discharge by length of stay. As length of stay increases, the probability of mortality increases (line)

Length of stay also contributed to patient outcomes. As LOS increased, there was a larger proportion of IHCA attributed to pulmonary and metabolic etiologies; conversely there was a downward trend in the percentage of cardiac and cerebral etiologies. This is similar to previous data describing the increased proportion of pulmonary etiologies as LOS increased. ${ }^{10}$ After adjusting for BMI, age, gender, and whether the patient was on a surgical or nonsurgical service, there was a significant increase in mortality following the initial IHCA as LOS increased. An international review of over four million admissions also found a correlation between increased LOS and mortality. ${ }^{14}$ We postulate these factors may be related to patient comorbidities, hospital-acquired aspiration, adverse in-hospital events, and hospital-acquired infections. With these data, healthcare providers should consider these pulmonary and metabolic etiologies more frequently in IHCA occurring in patients with a LOS $\geq 9$ days. Although monitoring in itself does not reduce the number of IHCA, the upward trend in the number of pulmonary etiologies identified in our population highlights the importance of monitoring oxygenation with the hope to more quickly identify and intervene on a pulmonary etiology for IHCA.

Our study used a similar approach to grouping the IHCA etiology to previous studies; however, there is variation in the literature of how this is categorized. ${ }^{4,10-12}$ When an identifiable etiology for IHCA was determined by the primary healthcare team, it was most commonly a pulmonary or cardiovascular cause 
consistent with prior investigations. ${ }^{10-12}$ We offer that a multisociety approved definition of different categories of causes and etiology will allow for more structured investigation and reporting, and potentially practice changing.

This study has multiple limitations, including a single-center academic institution with unique locoregional pathology. It has been established that regional differences, race, vasoactive medications, mechanical ventilation, age $\geq 65$ years old, timing (night and weekend), trauma centers, and teaching hospitals are associated with different cardiac arrest incidence and case survival. ${ }^{5,6,9}$ Witnessing the cardiac arrest and ratio of nurses to patients impact survival, which may play a role in our outcomes, but we were unable to identify what proportion of the IHCA occurred in and out of an intensive care setting to investigate this further. ${ }^{5}$ Also, some subgroups have lower sample size and are at risk for type II errors. Our study relied on direct documentation by the primary team or autopsy interpretation to decide the etiology of IHCA, which may be incorrect or incomplete and subsequently leading to confounding results. This raises the question again, if standardized documentation following a IHCA may provide more data and guide further studies. . $^{15,16}$

\section{Conclusion}

In-hospital cardiac arrest portends a poor prognosis with only $32.4 \%$ of our patients surviving to discharge. There was a significant difference in the outcome to discharge in favor of patients admitted to a surgical service compared with nonsurgical service. These findings are hypothesis-generating and further clinical trials should evaluate this further.

\section{Ethics Approval and Consent to Participate}

The need for approval to participate was waived by our institutional review board.

\section{ACKnOWLedgments}

We acknowledge the University of Florida Integrated Data Repository and the UF Health Office of the Chief Data Officer for providing the analytic data set for this project.

\section{References}

1. American College of Cardiology/American Heart Association Task Force on Clinical Data Standards (ACC/AHA/HRS Writing Committee to Develop Data Standards on Electrophysiology), Buxton AE, Calkins H, Callans JD, DiMarco JP, Fisher JD, et al. ACC/AHA/HRS 2006 key data elements and definitions for electrophysiological studies and procedures. a report of the american college of cardiology/american heart association task force on clinical data standards (acc/aha/hrs writing committee to develop data standards on electrophysiology). 2006;114(23):2534-2570. DOI: 10.1161/CIRCULATIONAHA.106.180199.

2. Al-Khatib SM, Stevenson WG, Ackerman MJ, Bryant WJ, Callans DJ, Curtis $A B$, et al. 2017 AHA/ACC/HRS guideline for management of patients with ventricular arrhythmias and the prevention of sudden cardiac death: executive summary. J Am Coll Cardi 2017;138(13): e201-e217.

3. Holmberg MJ, Ross CE, Fitzmaurice GM, Chan PS, DuvalArnould J, Grossestreuer AV, et al. Annual incidence of adult and pediatric in-hospital cardiac arrest in the United states. Cir Cardiovasc Qual Outcomes 2019;12(7):e005580. DOI: 10.1161/ CIRCOUTCOMES.119.005580.

4. Link MS, Berkow LC, Kudenchuk PJ, Halperin HR, Hess EP, Moitra VK, et al. Part 7: adult advanced cardiovascular life support. 2015 american heart association guidelines update for cardiopulmonary resuscitation and emergency cardiovascular care. Circulation 2015;132(18 suppl 2):S444-S464. DOI: 10.1161/CIR.0000000000000261.

5. Chen LM, Nallamothu BK, Spertus JA, Li Y, Chan PS. Association between a hospital's rate of cardiac arrest incidence and cardiac arrest survival. JAMA Intern Med 2013;173(13):1186-1195. DOI: 10.1001/ jamainternmed.2013.1026.

6. Ehlenbach WJ, Barnato AE, Curtis JR, Kreuter W, Koepsell TD, Deyo RA, et al. Epidemiologic study of in-hospital cardiopulmonary resuscitation in the elderly. N Engl J Med 2009;361(1):22-31. DOI: 10.1056/NEJMoa0810245.

7. Merchant RM, Yang L, Becker LB, Berg RA, Nadkarni V, Nichol G, et al. Incidence of treated cardiac arrest in hospitalized patients in the United states. Crit Care Med 2011;39(11):2401-2406. DOI: 10.1097/ CCM.0b013e3182257459.

8. Schultz SC, Cullinane DC, Pasquale MD, Magnant C, Evans SRT. Predicting in-hospital mortality during cardiopulmonary resuscitation. Resuscitation 1996;33(1):13-17. DOI: 10.1016/S03009572(96)00986-0.

9. Tian J, Kaufman DA, Zarich S, Chan PS, Ong P, Amoateng-Adjepong Y, et al. Outcomes of critically III patients who received cardiopulmonary resuscitation. Am J Respir Crit Care Med 2010;182(4):501-506. DOI: 10.1164/rccm.200910-16390C.

10. Tran S, Deacon N, Minokadeh A, Malhotra A, Davis DP, Villanueva S, et al. Frequency and survival pattern of in-hospital cardiac arrests: the impacts of etiology and timing. Resuscitation 2016;107:13-18. DOI: 10.1016/j.resuscitation.2016.07.006.

11. Wallmuller C, Meron G, Kurkciyan I, Schober A, Stratil P, Sterz F. Causes of in-hospital cardiac arrest and influence on outcome. Resuscitation 2012;83(10):1206-1211. DOI: 10.1016/j.resuscitation.2012.05.001.

12. Bergum D, Nordseth T, Mjølstad OC, Skogvoll E, Haugen BO. Causes of in-hospital cardiac arrest - incidences and rate of recognition. Resuscitation 2015;87:63-68. DOI: 10.1016/j.resuscitation.2014.11.007.

13. Bergum D, Haugen BO, Nordseth T, Mjølstad OC, Skogvoll E. Recognizing the causes of in-hospital cardiac arrest-a survival benefit. Resuscitation 2015;97:91-96. DOI: 10.1016/j.resuscitation.2015.09.395.

14. Lingsma HF, Bottle A, Middleton S, Kievit J, Steyerberg EW, Marang-van de Mheen PJ. Evaluation of hospital outcomes: the relation between length-of-stay, readmission, and mortality in a large international administrative database. BMC Health Serv Res 2018;18(1):116. DOI: 10.1186/s12913-018-2916-1.

15. Sukul D, Kamphuis LA, Iwashyna TJ, Bradley SM, Chan PS, Sinha SS, et al. Clinical documentation of in-hospital cardiac arrest in a large national health system. Resuscitation 2017;112:e9-e10. DOI: 10.1016/ j.resuscitation.2016.12.022.

16. Allan N, Bell D, Pittard A. Resuscitation of the written word: meeting the standard for cardiac arrest documentation. Clinl Med (Lond) 2011;11(4):348-352. DOI: 10.7861/clinmedicine.11-4-348. 